\title{
Perfil bioquímico sérico de gatos domésticos obesos oriundos da cidade de São Luís, Maranhão
}

\author{
Biochemical serum profile of obese domestic cats from São Luís city, Maranhão
}

\section{Dryane Silva Aguiar ${ }^{1}$, Mylena Andréa Oliveira Torres ${ }^{2}$, Daniel Praseres Chaves ${ }^{1}$, Nathálya dos Santos Martins $^{3}$, Erlin Cely Cotrim Cavalcante ${ }^{4}$ \& Tiago Silva Teofilo ${ }^{5^{*}}$}

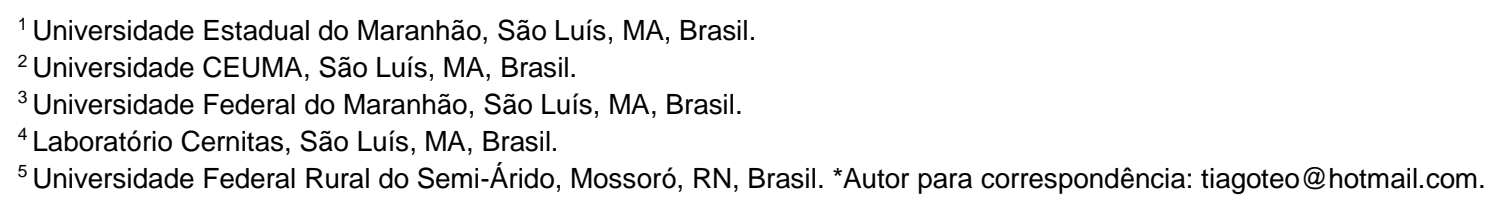

Submissão: 25/01/2017 / Aceite: 09/05/2018

\begin{abstract}
RESUMO
A obesidade é uma doença caracterizada pelo acúmulo excessivo de gordura corporal. É causada por múltiplos fatores, que podem levar ao desenvolvimento de várias enfermidades secundárias como as doenças cardíacas e do trato urinário inferior, dermatopatias, diabetes mellitus e lipidose hepática. Objetivou-se com este estudo avaliar as alterações bioquímicas séricas de gatos domésticos obesos. Para isso, foram utilizados 21 gatos domésticos, de ambos os sexos, sem raça definida, com idade entre 10 meses e 14 anos, escolhidos de acordo com o escore de condição corporal. Nesses animais foram realizadas avaliações clínicas e metabólicas. Notou-se quanto aos fatores de risco que $85,71 \%$ dos animais eram castrados, e que $52,38 \%$ dos animais possuíam hábitos sedentários. Para $71,43 \%$ dos machos e $100 \%$ das fêmeas eram fornecidas dietas exclusivas de ração e $42,86 \%$ dos gatos eram alimentados ad libitum. Os valores médios encontrados revelaram ureia e creatinina acima dos valores de referência, no qual os machos apresentaram valores mais elevados. A AST e ALT também apresentaram os valores acima dos valores normais para a espécie. Os valores de colesterol total, proteínas totais e frações (albumina e globulinas), glicose e fosfatase alcalina, quando se observou os valores mínimo e máximo mostraram resultados fora da normalidade para a espécie. Conclui-se que a obesidade pode alterar os valores bioquímicos séricos dos gatos demonstrando aumento do valor da ureia, creatinina, AST e ALT.
\end{abstract}

PALAVRAS-CHAVE: sobrepeso, Felis catus, análises bioquímicas.

\section{ABSTRACT}

Obesity is a disease characterized by excessive accumulation of body fat. It is caused by multiple factors, which can lead to the development of various secondary diseases such as heart disease and in the lower urinary tract, dermatopathies, diabetes mellitus and liver lipidosis. The aim of this study was to evaluate the biochemical serum profile of obese domestic cats. For this purpose, 21 domestic cats, of both sexes, with no defined breed, aged between 10 months and 14 years, were chosen according to the body condition score. Clinical and metabolic evaluations were performed in these animals. It was noted that $85.71 \%$ of the animals were castrated, and $52.38 \%$ of the animals had sedentary habits. For $71.43 \%$ of the males and $100 \%$ of the females were fed diets exclusive of feed and $42.86 \%$ of the cats were fed ad libitum. The mean values found showed urea and creatinine above the reference values, in which males presented higher values. AST and ALT also showed values above the normal values for the species. The values of total cholesterol, total proteins and fractions (albumin and globulins), glucose and alkaline phosphatase, when the minimum and maximum values were observed, showed non-normal results for the species. It is concluded that obesity can alter the biochemical serum values of the cats demonstrating increase in the value of urea, creatinine, AST and ALT.

KEYWORDS: overweight, Felis catus, biochemical analysis.

\section{INTRODUÇÃO}

A obesidade é caracterizada como uma doença, na qual há acúmulo excessivo de gordura, resultante 
de alteração ou desequilíbrio na ingestão de nutrientes ou distúrbios dos gastos energéticos, conduzindo ao ganho de peso do animal e mudanças na composição corporal (GUIMARÃES \& TUDURY 2006). Em felinos ocorre principalmente por um desequilíbrio energético, em que o gato consome mais energia do que gasta (MENDES 2013).

A obesidade se apresenta por um quadro de múltiplos fatores, que podem levar ao desenvolvimento de várias enfermidades secundárias como as doenças cardiovasculares, do trato urinário inferior, dermatopatias, diabetes mellitus, lipidose hepática, neoplasias e claudicações (LEWIS et al. 1994). Alguns fatores de origem metabólica e distúrbios endócrinos podem também estar relacionados ao desenvolvimento da obesidade como o hipopituitarismo, hipotireoidismo, hiperadrenocorticismo e hiperinsulinemia, pois essas doenças causam desequilíbrio energético, e consequente deposição de gordura e sobrepeso. Porém, essas alterações correspondem a uma parcela mínima, aproximadamente 5\% dos casos de obesidade canina e felina (GUIMARÃES \& TUDURY 2006).

A prevalência da obesidade é alta e está associada a vida sedentária e distúrbios metabólicos e endócrinos, bem como a falta de conhecimento do proprietário em relação a alimentação e a condição corporal do animal são fatores determinantes para seu aparecimento. Portanto, é primordial aos clínicos veterinários, que lidam cotidianamente com esses animais, um conhecimento profundo quanto às causas, os fatores de risco, o diagnóstico e o tratamento desta doença (MENDES 2013, LIMA 2013).

Diante disso, em gatos obesos a avaliação do perfil bioquímico sérico é de extrema importância para avaliar o estado de saúde (BECVAROVA 2011), auxiliando no diagnóstico de distúrbios hepáticos, renais, lipídicos e outros (NELSON \& COUTO 2010, OSBORNE et al. 2004). Dessa forma, são necessários estudos que avaliem alterações bioquímicas séricas que ocorrem em felinos obesos a fim de possibilitar diagnósticos de doenças associadas à obesidade. Com isso, objetivou-se avaliar o perfil bioquímico sérico de gatos domésticos (Felis catus) obesos, da cidade de São Luís, Maranhão.

\section{MATERIAL E MÉTODOS}

\section{Animais}

O estudo foi realizado com 21 gatos domésticos (Felis catus), adultos, de ambos os sexos, escolhidos de acordo com o escore de condição corporal (ECC), atendidos no Hospital Veterinário da Universidade Estadual do Maranhão (UEMA), provenientes de residências e de abrigos de animais, oriundos da cidade de São Luís, estado do Maranhão, Brasil.

Foram coletadas informações, de todos os gatos, sobre o ambiente em que viviam, se eram castrados ou não, sobre os hábitos alimentares e se apresentavam doenças intercorrentes. Todos os gatos foram pesados em balança digital e submetidos à avaliação clínica (cardiorrespiratória) e do ECC numa escala previamente descrita de 1 a 5 pontos, na qual os animais são classificados de caquéticos a obesos (BALDWIN et al. 2010). Foram escolhidos os gatos que apresentaram ECC 4 e 5, que corresponde a sobrepeso e obeso, respectivamente. Os animais com ECC 4, mostravam costelas difíceis de serem palpadas com moderada cobertura de gordura e reentrância abdominal mínima. Já os gatos classificados com ECC 5, apresentavam depósitos de gordura que dificultavam a palpação das costelas e o abdômen apresentava-se distendido com grandes depósitos de gordura.

Os animais utilizados apresentavam faixa etária de 10 meses de idade a 14 anos, sendo hígidos ou doentes, analisados durante o exame físico, onde foi observado o escore corporal, frequência respiratória e cardíaca.

\section{Coletas de amostras}

Foram colhidas amostras de sangue por punção da veia cefálica, jugular ou safena obtendo de 3 a $4 \mathrm{~mL}$. Os animais encontravam-se em jejum de aproximadamente 12 horas. As amostras foram armazenadas em tubos de coleta sem anticoagulante, conservadas sob refrigeração e encaminhadas ao laboratório veterinário (Cernitas, São Luís, MA), onde foram realizados os exames bioquímicos séricos.

\section{Exames Bioquímicos Séricos}

Os tubos contendo o sangue total foram centrifugados por 10 minutos a 2.500 rotações por minuto após a coleta para a obtenção do soro, conservadas em microtubos plásticos sob congelamento $\left(-20{ }^{\circ} \mathrm{C}\right)$ para processamento dos exames posteriormente.

Foram determinados nas amostras de soro sanguíneo dos gatos, glicose, colesterol total, proteína total e frações (albumina e globulinas), ureia, creatinina, fosfatase alcalina (FA), alanina aminotransferase (ALT) e aspartato aminotransferase (AST). As dosagens dos exames bioquímicos séricos foram feitas mediante analisador bioquímico Bio Plus semiautomático modelo BIO-200, com exceção da glicose que foi analisada pelo espectrofotômetro, de acordo com a técnica descrita por MEYER et al. (1995). 
Os valores encontrados foram interpretados em comparação com valores de referência estabelecidos pelo Laboratório Cernitas (São Luís, MA) e submetidos à análise estatística descritiva, tais como média, desvio padrão, erro-padrão, valores mínimo e máximo e coeficiente de variação.

\section{Análises estatísticas}

Os resultados obtidos foram submetidos à análise estatística descritiva, sendo expressos em médias, com seus respectivos desvios e erros padrões, bem como valores máximos e mínimos observados, utilizando o software estatístico IBM SPSS Statistics, versão 20.

\section{RESULTADOS E DISCUSSÃO}

No presente estudo, não foi possível determinar o período da vida no qual os animais se tornaram obesos. Os valores de idade, peso, circunferência abdominal, escore de condição corporal (ECC) e as frequências cardíaca e respiratória dos gatos utilizados estão apresentados na Tabela 1, sendo divididos de acordo com o sexo.

Tabela 1. Parâmetros físicos e clínicos de gatos obesos, provenientes de São Luís, MA.

Table 1. Physical and clinical parameters of obese cats from São Luís, MA.

\begin{tabular}{lcccc}
\hline & \multicolumn{2}{c}{ Machos $(\mathrm{N}=14)$} & \multicolumn{2}{c}{ Fêmeas $(\mathrm{N}=7)$} \\
& Média & DP ${ }^{1}$ & Média & $\mathrm{DP}^{1}$ \\
\hline Idade (anos) & 5,35 & 2,70 & 6,67 & 3,78 \\
Peso $(\mathrm{kg})$ & 6,01 & 0,73 & 5,36 & 0,45 \\
Circ. Abd. $^{2}(\mathrm{~cm})$ & 48,68 & 1,23 & 47,50 & 1,38 \\
$\mathrm{ECC}^{3}$ & 4,57 & 0,51 & 4,29 & 0,48 \\
$\mathrm{FR}^{4}(\mathrm{mpm})$ & 13,50 & 2,76 & 14,43 & 2,63 \\
$\mathrm{FC}^{5}(\mathrm{bpm})$ & 124,00 & 14,83 & 130,28 & 22,41 \\
\hline
\end{tabular}

iDesvio padrão; ${ }^{2}$ Circunferência abdominal; ${ }^{3}$ Escore de condição corporal; ${ }^{4}$ Frequência cardíaca; ${ }^{5}$ Frequência respiratória.

Observou-se média de idade 5,35 $\pm 2,70$ anos para os machos e 6,67 $\pm 3,78$ anos para as fêmeas. $O$ peso corporal médio dos machos foi de $6,01 \pm 0,73 \mathrm{~kg}$ e das fêmeas $5,36 \pm 0,45 \mathrm{~kg}$. Os gatos demonstraram circunferência abdominal de 48,68 $\pm 1,23 \mathrm{~cm}$ e 47,50 $\pm 1,38 \mathrm{~cm}$ para machos e fêmeas, respectivamente. O ECC nos machos mostrou-se com valor médio de 4,57 $\pm 0,51$ e para as fêmeas 4,29 \pm 0,48 . Os valores da frequência respiratória foram de $13,50 \pm 2,76$ movimentos por minuto ( $\mathrm{mpm}$ ) nos machos e 14,43 $\pm 2,63 \mathrm{mpm}$ nas fêmeas.

A raça e idade não foram avaliadas como um fator de risco neste estudo, uma vez que nenhum gato estudado era de raça pura e com idades variadas. Alguns autores afirmam que animais adultos são mais predispostos a serem obesos, devido a redução do gasto energético (RUSSELL et al. 2000, LUND et al. 2005).

A frequência cardíaca apresentou-se dentro dos valores normais (120 a $240 \mathrm{bpm}$ ) como observado por FEITOSA (2008). Os demais parâmetros clínicos quando avaliados também apresentaram os valores dentro da normalidade para a espécie (FEITOSA 2008).

Entre os 14 machos, 12 eram castrados $(85,71 \%)$ e entre as sete fêmeas, seis eram castradas (85,71\%). De acordo com GERMAN (2006), a castração em ambos os sexos é um fator de risco para a obesidade, pois esse procedimento é responsável pela diminuição da taxa metabólica basal, e consequentemente pelo aumento da ingestão de alimentos e o sedentarismo.

Quanto ao hábito de exercitar-se, sete machos $(50 \%)$ e quatro fêmeas $(57,14 \%)$ foram relatados como sedentários. Dois animais (9,52\%) viviam em abrigos, três (14,29\%) em apartamentos e $16(76,19 \%)$ em casas. A redução de atividades físicas, associada ao avanço da idade e a criação de gatos em ambientes fechados com pouco enriquecimento ambiental são fatores predisponentes para 0 desenvolvimento da obesidade (LAFLAMME 2010).

O manejo alimentar pode influenciar no ganho de peso em gatos (RUSSELL et al. 2000). No presente estudo, todas as fêmeas eram alimentadas com ração comercial para gatos adultos, e entre os machos, 10 eram alimentados com ração $(71,43 \%)$, três com uma mistura de ração comercial e comida caseira $(21,43 \%)$ e um gato com resto de comida caseira $(7,14 \%)$. Em relação à frequência alimentar, de ambos os sexos, três animais $(14,29 \%)$ eram alimentados três vezes ao dia, nove $(42,86 \%)$ duas vezes ao dia e nove gatos (42,86\%) ad libitum. De acordo com GERMAN (2010) e ZORAN (2009), a alimentação ad libitum deve ser evitada para animais com predisposição à obesidade, ou que já apresentam sobrepeso, assim como para gatos sedentários, criados em ambientes fechados e castrados.

Alguns animais apresentavam outras doenças. Três fêmeas $(42,86 \%)$ possuíam rinotraqueite, um 
(14,29\%) infecção urinária e um (14,29\%) lipidose, o restante não apresentaram histórico de doenças. Entre os machos, um $(7,14 \%)$ havia apresentado histórico de sarna, um $(7,14 \%)$ de cistite, um $(7,14 \%)$ de leucemia felina (Felv) e quatro $(28,57 \%)$ de infecção urinária.

De acordo com HAND et al. (2010), a obesidade é considerada um fator de risco para a formação de cálculos urinários, na qual, gatos com excesso de peso são mais predispostos a desenvolverem cálculos de oxalato de cálcio que gatos com peso ideal. Além disso, gatos obesos são mais susceptíveis a desenvolver outras doenças do trato urinário, como cistite aguda, urolitíase, doença do trato urinário inferior idiopática felina, obstrução urinária, cistite idiopática e infecção do trato urinário (SANTOS 2014).

O valor de ureia sérica dos gatos foram superiores aos de referência, mostrando média de $68,95 \pm$ $104,19 \mathrm{mg} / \mathrm{dL}$, e os valores mínimo e máximo encontrados foram de $27,00 \mathrm{mg} / \mathrm{dL}$ e $515,00 \mathrm{mg} / \mathrm{dL}$, respectivamente (Tabela 2). Quando analisado de acordo com o sexo (Tabela 3), apenas os machos apresentavam valores aumentados $(81,71 \pm 127,06 \mathrm{mg} / \mathrm{dl})$. Alguns fatores alimentares podem alterar a ureia sérica, uma vez que a produção de ureia apresenta aumento em condições de ingestão protéica elevada e diminui em condições de baixa ingestão (OLIVEIRA 2004).

Tabela 2. Perfil bioquímico de gatos obesos, São Luís, MA.

Table 2. Biochemical profile of obese cats, São Luís, MA.

\begin{tabular}{lrrrrc}
\hline & Média & \multicolumn{1}{c}{$\mathrm{DP}^{1}$} & Mínimo & Máximo & Referência \\
\hline Ureia & 68,95 & 104,19 & 27,00 & 515,00 & $42,80-64,2$ \\
Creatinina & 1,91 & 2,58 & 0,80 & 13,13 & $0,5-1,8$ \\
Colesterol & 116,14 & 65,61 & 41,90 & 288,00 & $95-130$ \\
Glicose & 76,84 & 26,55 & 41,90 & 127,00 & $73-134$ \\
Proteínas totais & 6,93 & 0,99 & 5,37 & 9,09 & $5,8-7,9$ \\
Albumina & 2,20 & 1,27 & 1,00 & 5,90 & $1,9-3,8$ \\
Globulinas & 4,74 & 1,53 & 1,15 & 6,96 & $2,6-5,1$ \\
AST $^{2}$ & 41,40 & 19,54 & 10,00 & 82,00 & $9,2-39,5$ \\
ALT $^{3}$ & 91,62 & 59,57 & 26,00 & 277,00 & $<50$ \\
FA $^{4}$ & 12,57 & 5,28 & 5,00 & 25,00 & $12-65,1$ \\
\hline
\end{tabular}

'Desvio padrão; ${ }^{2}$ Aspartato aminotransferase; ${ }^{3}$ Alanina aminotransferase; ${ }^{4}$ Fosfatase alcalina. Valores de referência: Laboratório Cernitas, São Luís, MA.

Os valores de creatina também estavam aumentados nos machos, com valor médio de 2,23 $\pm 3,14$ $\mathrm{mg} / \mathrm{dl}$ (Tabela 3). Entretanto, alguns trabalhos apontam que a concentração sérica da creatinina não é afetada pela dieta ou qualquer outro fator que afete o metabolismo hepático ou o ciclo da ureia (OLIVEIRA 2004).

Tabela 3. Perfil bioquímico de gatos obesos de acordo com o sexo, São Luís, MA.

Table 3. Biochemical profile of obese cats according to sex, São Luís, MA.

\begin{tabular}{lrrrrrrc}
\hline \multicolumn{3}{c}{ Machos $(\mathrm{N}=14)$} & \multicolumn{3}{c}{ Fêmeas $(\mathrm{N}=7)$} & Referência \\
\hline & Média & \multicolumn{1}{c}{$\mathrm{EPM}^{1}$} & \multicolumn{1}{c}{$\mathrm{DP}^{2}$} & \multicolumn{1}{c}{ Média } & \multicolumn{1}{c}{ EPM } & \multicolumn{1}{c}{$\mathrm{DP}$} & \\
\hline Ureia & 81,71 & 33,96 & 127,06 & 43,43 & 3,11 & 8,22 & $42,80-64,2$ \\
Creatinina & 2,23 & 0,84 & 3,14 & 1,27 & 0,09 & 0,25 & $0,5-1,8$ \\
Colesterol & 116,99 & 20,66 & 77,30 & 114,43 & 14,14 & 37,41 & $95-130$ \\
Glicose & 79,93 & 7,46 & 27,92 & 70,65 & 9,21 & 24,36 & $73-134$ \\
Proteínas totais & 6,73 & 0,24 & 0,91 & 7,35 & 0,41 & 1,10 & $5,8-7,9$ \\
Albumina & 2,41 & 0,37 & 1,38 & 1,78 & 0,37 & 0,99 & $1,9-3,8$ \\
Globulinas & 4,31 & 0,42 & 1,57 & 5,61 & 0,40 & 1,07 & $2,6-5,1$ \\
AST $^{3}$ & 40,88 & 5,34 & 20,00 & 42,48 & 7,60 & 20,10 & $9,2-39,5$ \\
ALT $^{4}$ & 97,21 & 18,07 & 67,59 & 80,43 & 15,63 & 41,36 & $<50$ \\
FA $^{5}$ & 12,36 & 1,23 & 4,58 & 13,00 & 2,59 & 6,86 & $12-65,1$ \\
\hline
\end{tabular}

${ }^{1}$ Erro padrão da média; ${ }^{2}$ Desvio padrão; ${ }^{3}$ Aspartato aminotransferase; ${ }^{4}$ Alanina aminotransferase; ${ }^{5}$ Fosfatase alcalina. Valores de referência: Laboratório Cernitas, São Luís, MA.

A azotemia é o parâmetro laboratorial que melhor indica problemas relacionados com o sistema urinário e pode ter origem pré-renal, renal e pós-renal, o que justifica os valores observados no trabalho, uma vez que alguns animais apresentavam doenças associadas ao sistema urinário. A azotemia pré-renal normalmente está relacionada a hipovolemia, como em casos de desidratação e choque. A azotemia renal é 
causada por lesões que podem ocorrer nos glomérulos, túbulos, interstício, pelve renal ou vasos sanguíneos. Já a azotemia pós-renal pode ser decorrente de obstrução em qualquer local após o néfron ou na ruptura de estruturas do sistema urinário (THRALL et al. 2015).

Os valores de AST e ALT nos animais analisados de ambos os sexos foram superiores aos valores de referência (Tabelas 2 e 3). Em relação a AST, os machos apresentaram valores médios de 40,88 $\pm 20,00$ $\mathrm{U} / \mathrm{L}$ e as fêmeas $42,48 \pm 20,10 \mathrm{U} / \mathrm{L}$ (Tabela 3). Em relação a ALT, a média foi de $97,21 \pm 67,59 \mathrm{U} / \mathrm{L}$ e 80,43 $\pm 41,36 \mathrm{U} / \mathrm{L}$ nos machos e fêmeas, respectivamente (Tabela 3). Em gatos a ALT é mais hepatoespecífica do que a AST. O aumento da atividade sérica da ALT e AST, em geral, pode indicar destruição dos hepatócitos, mas também pode ser relacionado à necrose ou lesão muscular extensa, no entanto, a magnitude de aumento de AST é menor que a induzida pela ALT. Em casos de aumento da atividade da ALT, é importante mensurar a atividade sérica de uma enzima mais específica para lesão muscular, como creatinoquinase (MEYER et al. 1995, THRALL et al. 2015).

O colesterol, a fosfatase alcalina, as proteínas totais e frações (albumina, globulinas), estavam dentro dos padrões de normalidade (Tabela 2). Quando analisado de acordo com o sexo (Tabela 3), foram observadas hipoalbuminemia e hiperglobulinemia nas gatas. As alterações nas concentrações séricas destas variáveis, como podem ser evidenciadas pelos valores mínimos e máximos observados (Tabela 2), que podem ter ocorrido devido as comorbidades associadas. A concentração de colesterol nos gatos apresentou mínima de $41,90 \mathrm{mg} / \mathrm{dl}$ e máximo de $288,00 \mathrm{mg} / \mathrm{dl}$. A proteína total revelou concentração mínima de 5,37 g/dl e máxima de $9,09 \mathrm{~g} / \mathrm{dl}$, e as frações da proteína mostraram concentração mínima de $1,00 \mathrm{~g} / \mathrm{dl}$ e máxima de 5,90 $\mathrm{g} / \mathrm{dl}$ para as albuminas e mínima de 1,15 g/dl, máxima de 6,96 $\mathrm{g} / \mathrm{dl}$ para as globulinas.

O valor de glicose permaneceu dentro dos valores de referência, demonstrando valor de 76,84 \pm $26,55 \mathrm{mg} / \mathrm{dl}$ (Tabela 2). A glicemia de gatos com mais de nove meses de obesidade instalada normalmente encontra-se dentro dos padrões de normalidade, porém dados da literatura mostram que os níveis de insulina normalmente apresentam-se aumentados. Este fato se deve a resposta destes animais a insulina, elevando a oxidação de gorduras para produção de energia e não a oxidação de glicose, no entanto, em machos a oxidação de gorduras é limitada (HOENIG et al. 2007).

\section{CONCLUSÃO}

A obesidade pode interferir nos valores bioquímicos séricos dos gatos demonstrando elevação da ureia, creatinina, AST e ALT. Pesquisas específicas sobre obesidade em gatos são escassas, e muito do que se encontra na literatura é extrapolação de outras espécies mais pesquisadas. Os gatos apresentam peculiaridades nutricionais e fisiológicas, e por isso pouco se sabe sobre os mecanismos fisiopatológicos envolvidos na espécie, sendo necessárias novas pesquisas.

\section{REFERÊNCIAS}

BALDWIN K et al. 2010. AAHA Nutritional Assessment Guidelines for Dogs and Cats. Journal of the American Animal Hospital Association, Lakewood 46: 285-296.

BECVAROVA I. 2011. Canine and feline obesity: Frequently asked questions ad their answers. Compendium: Continuing Education for Veterinarians 33: 1-5.

FEITOSA FLF. 2008. Semiologia Veterinária: A arte do diagnóstico. São Paulo: Editora Roca. 754p.

GERMAN A. 2006. Clinical risks associated with obesity in companion animals. Waltham Focus 16: 21-26.

GERMAN A. 2010. Obesity in companion animals. In Practice 32: 42-50.

GUIMARÃES ALN \& TUDURY EA. 2006. Etiologias, consequências e tratamentos de obesidades em cães e gatos revisão. Veterinária Notícias 12: 29-41.

HAND MS et al. 2010. Small Animal Clinical Nutrition. 5th ed. Kansas: Mark Morris Institute. 1314p.

HOENIG M et al. 2007. Insulin sensitivity, fat distribution, and adipocytokine response to different diets in lean and obese cats before and after weight loss. American Journal of Physiology. Regulatory, Integrative and Comparative Physiology 292: 227-234.

LAFLAMME DP. 2010. Cats and carbohydrates: Implications for health and disease. Compendium: Continuing Education for Veterinarians 32: 1-3.

LEWIS LD et al. 1994. Obesity. In: LEWIS LD et al. (Eds.). Small Animal Clinical Nutrition III. Kansas: Mark Morris Institute. p. 1-39.

LIMA FS de. 2013. Obesidade em cães e gatos: revisão de literatura. Monografia (Graduação em Medicina Veterinária). São Luís: UEMA. 40p.

LUND EM et al. 2005. Prevalence and risk factors for obesity in adult cats from private US veterinary practices. The International Journal of Applied Research in Veterinary Medicine 3: 88-96.

MENDES FF et al. 2013. Obesidade felina. Enciclopédia Biosfera 9: 1602-1625. 
MEYER DJ et al. 1995. Medicina de laboratório veterinário. Interpretação e diagnóstico. São Paulo: Roca. 308p.

NELSON RW \& COUTO CG. 2010. Medicina interna de pequenos animais. 4.ed. Rio de Janeiro: Elsevier. 1504p.

OSBORNE CA et al. 2004. Doenças do trato urinário inferior dos felinos. In: ETTINGER SJ \& FELDMAN EC. Tratado de medicina interna veterinária: doenças do cão e do gato. 5.ed. Rio de Janeiro: Guanabara Koogan. p.1802-1841.

OLIVEIRA ST. 2004. Alterações de compostos nitrogenados não protéicos em cães e gatos. Seminário de Transtornos Metabólicos dos Animais Domésticos, PPGCV/UFRGS. 17p.

RUSSELL K et al. 2000. Influence of feeding regimen on body condition in the cat. Journal of Small Animal Practice 41: 12-17.

SANTOS AF. 2014. Obesidade em cães e gatos. Universidade Anhembi Morumbi, São Paulo. Disponível em: <http://www.cachorrosaude.com.br/obesidade-em-caes-e-gatos/> Acesso em: 27 Mar. 2016.

THRALL MA et al. 2015. Hematologia e bioquímica clínica veterinária. 2.ed. São Paulo: Roca. 688p.

ZORAN D. 2009. Feline obesity: clinical recognition and management. Compendium: Continuing Education for Veterinarians. p. 284-291. 